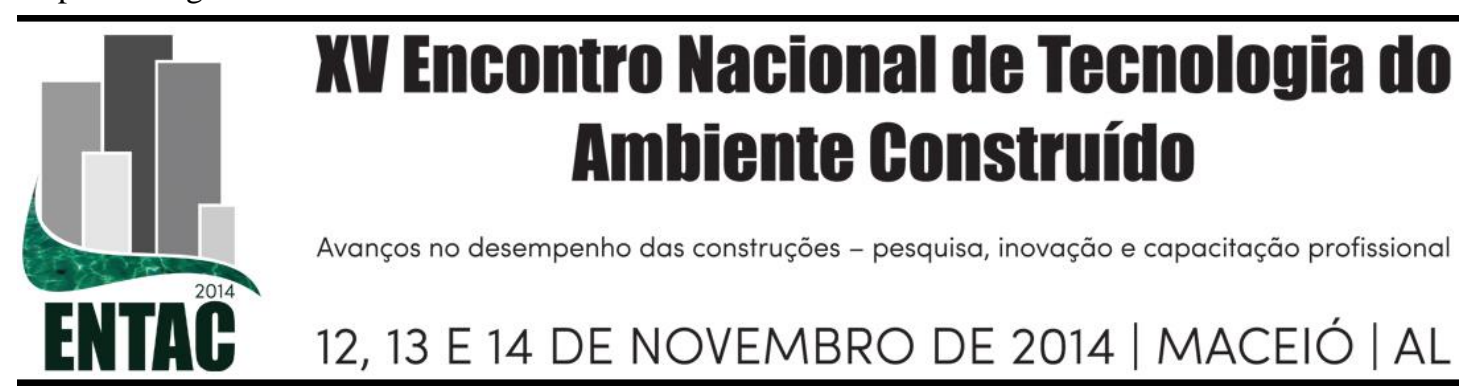

\title{
EFEITO DE VARIAÇÕES NO PROJETO DE ARQUITETURA DE UMA HABITAÇÃO NO SEU DESEMPENHO TÉRMICO
}

\author{
SALES, Elisa M. (1); BRITO, Adriana C. (2); AKUTSU, Maria (3) \\ (1) IPT, elisams@ipt.br (2) IPT, adrianab@ipt.br (3) IPT, akutsuma@ipt.br
}

\begin{abstract}
RESUMO
Neste artigo são apresentadas análises do desempenho térmico de uma habitação considerando-se dois sistemas construtivos com inércias térmicas significativamente diferentes (sistema "leve" e sistema "pesado") e variações no seu projeto arquitetônico, com o objetivo de evidenciar o efeito destas variáveis na resposta térmica da edificação. São contempladas as seguintes possibilidades: variação proporcional do tamanho dos ambientes e das aberturas em relação a uma condição padrão; alteração da proporção de área envidraçada na fachada em relação ao tamanho dos ambientes e variações no pé direito dos ambientes. A resposta térmica da edificação foi obtida por meio de simulações computacionais como o programa EnergyPlus que considera regime transiente de trocas térmicas, considerando-se as condições climáticas da cidade de São Paulo. Os resultados indicam que sistemas construtivos leves são mais afetados por variações nos parâmetros de projeto considerados.
\end{abstract}

Palavras-chave: desempenho térmico, habitação, inércia térmica, projeto.

\begin{abstract}
We evaluated the effect of some design variables on the thermal performance of a typical Brazilian dwelling made of lightweight and heavyweight components. The variables analyzed were the size of the building, the ceiling height and façade's glazing area. The building thermal response was obtained by computer simulations considering the climatic conditions of the São Paulo City. The results show that the building made of lightweight components is most affected by design variations.
\end{abstract}

Keywords: thermal performance, dwelling, thermal mass, building design.

\section{INTRODUÇÃO}

O desempenho térmico de uma edificação depende de fatores como as condições climáticas do local, o projeto arquitetônico e o sistema construtivo empregado nas suas vedações. Os dois últimos são praticamente indissociáveis, especialmente, quando se tratam de edifícios de pequeno porte, como as habitações de interesse social em que a envoltória é fator determinante das condições térmicas nos ambientes.

Contudo, quando se avalia o desempenho térmico potencial de um sistema construtivo que será aplicado em edificações em fase de projeto, ainda sujeitas a alterações, buscam-se informações que tornem o resultado dessas avaliações o mais generalizável possível, desvinculando-o de projetos de arquitetura específicos. O empreendedor almeja ter liberdade para alterar algumas características, como as dimensões dos cômodos e das aberturas e o pé direito e até mesmo o sistema construtivo utilizado, em função de suas necessidades. Este é um desejo conflitante com a realidade física, que tem demonstrado que, algumas alterações, até efetuadas no momento da construção do edifício, podem ter grande impacto no desempenho térmico da edificação. 
Estas questões são apresentadas por autores como Verbeke (2010), Gregory et Al. (2008), Chan et al. (1999), por exemplo, que demonstram os efeitos de algumas variáveis de projeto no desempenho térmico / energético de edificações habitacionais.

Verbeke (2010) analisou o efeito da inércia térmica de paredes, da orientação solar e da área envidraçada da fachada na eficiência energética e no conforto térmico dos usuários de dois tipos de habitações na Bélgica. $\mathrm{O}$ autor considerou residências com paredes leves em placas de madeira e com paredes pesadas em alvenaria de tijolos cerâmicos. $\mathrm{O}$ autor indica que, de maneira geral, com as paredes mais leves os usuários têm $20 \%$ mais desconforto térmico.

Gregory et al. (2007) verificaram o efeito de variações na inércia térmica das paredes e na área envidraçada da envoltória na resposta térmica das habitações. Os autores consideraram paredes com elementos cerâmicos em quatro configurações de modo a se obter paredes leves e pesadas. Os resultados indicam que nas habitações com paredes mais pesadas há um amortecimento mais significativo das amplitudes diárias das temperaturas do ar interior e têm seu desempenho térmico menos afetado pela variação da área envidraçada na envoltória. Os autores indicam que à medida que se aumenta a área envidraçada na fachada, é necessário aumentar também a capacidade térmica das paredes para obter condições térmicas no interior dos ambientes mais adequadas ao conforto térmico humano.

Chan et al. (1999), analisou a resposta térmica de uma habitação mexicana considerando dois tipos de paredes com diferentes capacidades térmicas: blocos vazados de concreto e tijolo cerâmico maciço. Os resultados indicam que as paredes de tijolo cerâmico maciço, que possuem maior capacidade térmica, proporcionaram menor demanda para resfriamento de ambientes, indicando a importancia da inércia térmica do sistema construtivo na eficiência energética da habitação.

Neste trabalho tem-se como objetivo verificar o efeito de variações na inércia térmica e no projeto arquitetônico de uma habitação de interesse social no seu desempenho térmico considerando os critérios apresentados na norma brasileira NBR 15575 Edificações Habitacionais - Desempenho (ABNT, 2013).

\section{MÉTODO DE TRABALHO}

Foi analisado o desempenho térmico de uma habitação típica (CDHU, 1997), como indicado na Figura 1, considerando-se duas opções de sistemas construtivos, com inércia térmica substancialmente distinta, ou seja, um "leve" e outro "pesado", variando-se ainda elementos do projeto arquitetônico referentes às dimensões dos ambientes e à área envidraçada na fachada.

Nos itens 2.1 e 2.2 são apresentados, respectivamente, os procedimentos para a avaliação do desempenho térmico da edificação e a descrição dos sistemas construtivos utilizados e, nos itens 2.3 a 2.5, são indicadas as variáveis de projeto arquitetônico consideradas nas análises. 
Figura 1 - Projeto da habitação, sem escala.

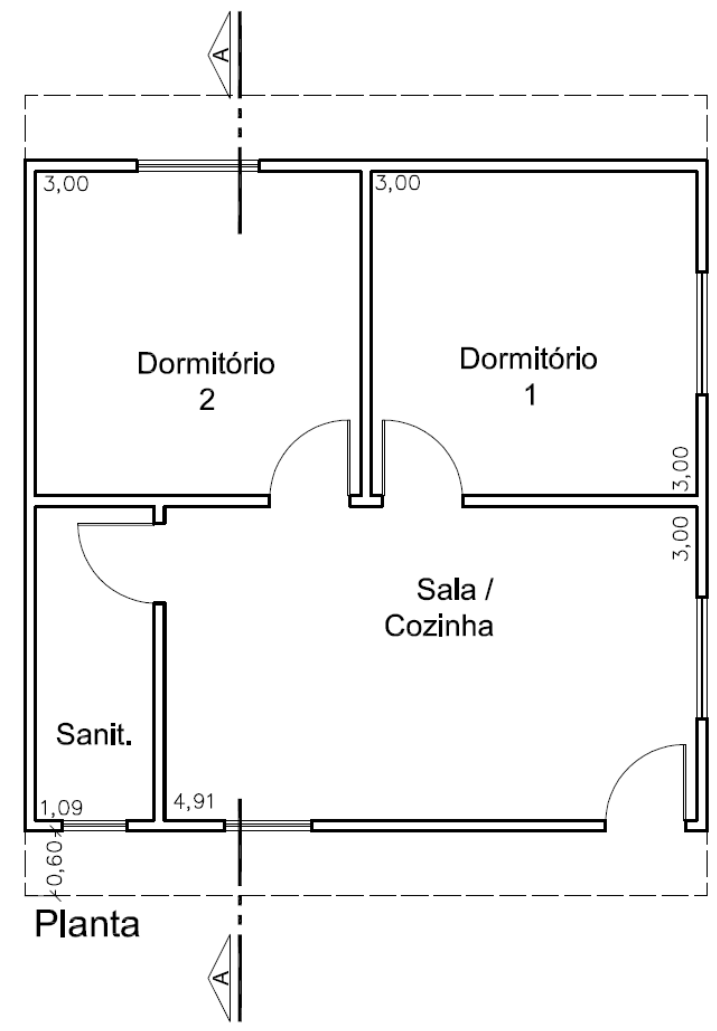

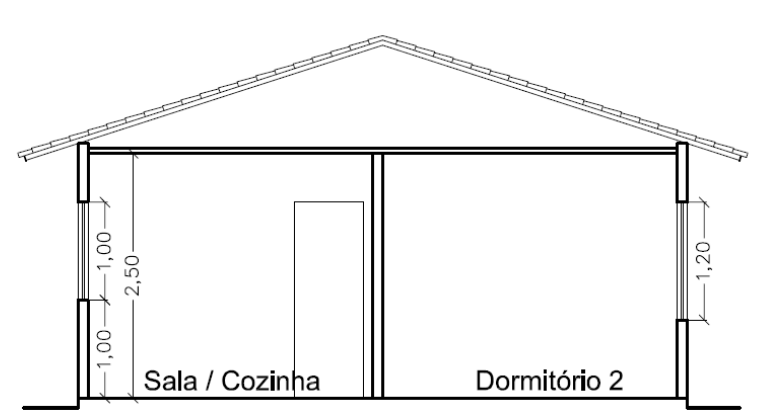

Corte A

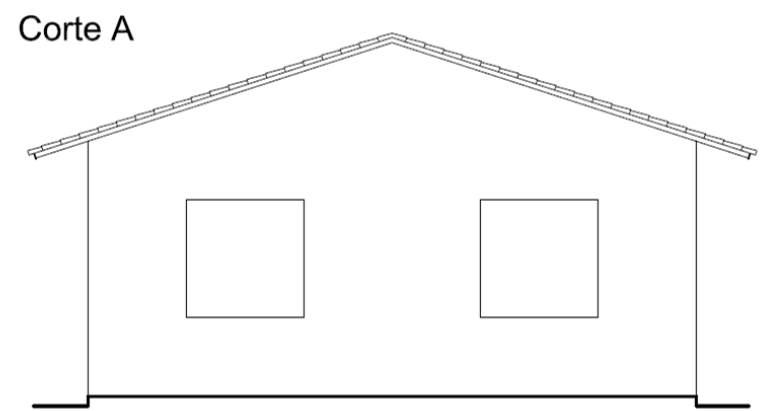

Fachada Principal

Fonte: Adaptado de CDHU (1997).

\subsection{Procedimentos para análise do desempenho térmico de habitação por simulação computacional}

Foram realizadas simulações computacionais da resposta térmica da edificação utilizando-se o programa EnergyPlus que leva em conta o caráter dinâmico das trocas de calor entre a edificação e o ambiente externo. Foram simulados todos os ambientes da edificação, cada qual como uma zona térmica, de modo a considerar as trocas de calor entre todas as superfícies dos recintos.

O desempenho térmico da habitação foi analisado a partir de resultados das simulações computacionais da resposta térmica de dois recintos, dormitório e sala de estar, de 
acordo com os procedimentos apresentados na Norma ABNT NBR 15575 (ABNT, 2013). Foram determinados os valores horários das temperaturas do ar exterior e do ar interior dos referidos recintos, analizados conforme os critérios presentes na referida norma e apresentados no item 2.1.2.

Foram consideradas as condições climáticas da cidade de São Paulo - SP, representando a Zona Bioclimática Brasileira 3 (ABNT, 2013), caracterizadas pelos valores horários da temperatura, da umidade relativa do ar e da radiação solar global nos "dias típicos de projeto", conforme a norma ABNT NBR 15575 (ABNT, 2013). Os dados geográficos desta cidade são apresentados na Tabela 1 e os dados climáticos dos dias típicos de verão e de inverno são indicados na Tabela 2.

Tabela 1 - Dados geográficos da cidade.

\begin{tabular}{|l|l|l|l|l|}
\hline Cidade & UF & Latitude & Longitude & $\begin{array}{l}\text { Altitude } \\
(\mathbf{m})\end{array}$ \\
\hline São Paulo & SP & $23,5 \mathrm{~S}$ & $46,62 \mathrm{~W}$ & 792 \\
\hline
\end{tabular}

Tabela 2 - Dados climáticos de dias típicos de verão e de inverno da cidade.

\begin{tabular}{|c|c|c|c|c|c|}
\hline \multirow{2}{*}{ Cidade } & Período & $\begin{array}{c}\text { Temperatura } \\
\text { máxima do } \\
\mathbf{a r} \\
\left({ }^{\mathbf{0}} \mathbf{C}\right)\end{array}$ & $\begin{array}{c}\text { Amplitude } \\
\text { diária } \\
\text { da } \\
\text { temperatura } \\
\mathbf{d o} \text { ar } \\
\left.\mathbf{(}^{\mathbf{0}} \mathbf{C}\right)\end{array}$ & $\begin{array}{c}\text { Temperatura } \\
\text { de bulbo } \\
\text { úmido } \\
\left({ }^{\mathbf{0}} \mathbf{C}\right)\end{array}$ & $\begin{array}{c}\text { Radiação } \\
\text { solar global } \\
\text { plano } \\
\text { horizontal } \\
\left(\mathbf{W h} / \mathbf{m}^{2}\right)\end{array}$ \\
\hline \multirow{2}{*}{ São Paulo } & Verão & 31,9 & 9,2 & 21,3 & 5180 \\
\cline { 2 - 6 } & Inverno & 16,2 & 10,0 & 13,4 & 4418 \\
\hline
\end{tabular}

Fonte: ABNT (2013).

\subsubsection{Condições analisadas}

Foram fixadas condições referentes à orientação das janelas dos recintos, à ventilação dos ambientes e ao sombreamento das aberturas para proporcionar a verificação somente dos efeitos de variações no sistema construtivo e dimensões de ambientes e janelas no desempenho térmico da edificação. Foram adotados os seguintes parâmetros:

- Orientação solar: os ambientes foram simulados com as janelas dos dormitórios e sala voltadas à direção Oeste no período de verão e a Sul no período de inverno, representando condições mais críticas de exposição à radiação solar, de acordo com a Norma ABNT NBR 15575 (ABNT, 2013). Nos casos em que há mais de uma janela no recinto, aquela com maior área envidraçada é voltada à direção Oeste; 
- Taxa de ventilação dos ambientes e sombreamento de aberturas: considerou-se uma taxa de ventilação correspondente a uma renovação do volume do ambiente por hora (1 Ren/h), que corresponde a ventilação somente por infiltração através de frestas em janelas e portas; as janelas não possuem elementos de sombreamento conforme indicado na Norma ABNT NBR 15575 (ABNT, 2013).

\subsubsection{Critérios de avaliação}

O critério de avaliação de edificações não condicionadas apresentado no Anexo $\mathrm{E}$ da Norma ABNT NBR 15575-1 (ABNT, 2013), classifica o desempenho térmico da edificação em função do seu comportamento nos dias típicos de verão e de inverno, segundo três níveis: "M" (Mínimo), "I" (Intermediário) ou "S" (Superior), adotando-se como parâmetro de avaliação, a temperatura do ar interior.

Para a Zona Bioclimática 3, os critérios referem-se aos períodos de verão e inverno, conforme disposto a seguir:

- Verão:

○ $\quad$ Nível "M": quando o valor máximo diário da temperatura do ar interior é menor ou igual ao valor máximo diário da temperatura do ar exterior e maior que o valor limite estipulado para o nível "I";

○ $\quad$ Nível "I": quando o valor máximo diário da temperatura do ar interior é pelo menos $2{ }^{\circ} \mathrm{C}$ menor que o valor máximo diário da temperatura do ar exterior e maior que o valor limite estipulado para o nível "S";

- $\quad$ Nível "S": quando o valor máximo diário da temperatura do ar interior é pelo menos $4{ }^{\circ} \mathrm{C}$ menor que o valor máximo diário da temperatura do ar exterior;

- Inverno:

○ Nível "M": quando o valor mínimo diário da temperatura do ar interior é pelo menos $3{ }^{\circ} \mathrm{C}$ maior que o valor mínimo diário da temperatura do ar exterior e menor que o valor limite estipulado para o nível "I";

○ $\quad$ Nível "I": quando o valor mínimo diário da temperatura do ar interior é pelo menos $5{ }^{\circ} \mathrm{C}$ maior que o valor mínimo máximo diário da temperatura do ar exterior e menor que o valor limite estipulado para o nível "S";

- Nível "S": quando o valor mínimo diário da temperatura do ar interior é pelo menos $7{ }^{\circ} \mathrm{C}$ maior que o valor mínimo diário da temperatura do ar exterior.

\subsection{Sistema construtivo}

- Leve:

- Paredes externas: compostas por chapas cimentícias com espessura de $10 \mathrm{~mm}$ na face externa (massa específica da ordem de $1600 \mathrm{~kg} / \mathrm{m}^{3}$ ) e placa de gesso acartonado, com 
espessura de $12,5 \mathrm{~mm}$, na face interna. As placas estão posicionadas a uma distância de $9 \mathrm{~cm}$ entre si, com o interior preenchido com lã de vidro com espessura de $5 \mathrm{~cm}$ e massa específica da ordem de $12 \mathrm{~kg} / \mathrm{m}^{3}$ e condutividade térmica de $0,04 \mathrm{~W} /\left(\mathrm{m}^{\circ} \mathrm{C}\right)$. O acabamento externo das paredes é em cores claras;

- Paredes internas: compostas por placas de gesso acartonado, com espessura de $12,5 \mathrm{~mm}$, posicionadas a uma distância de $9 \mathrm{~cm}$ entre si;

- Cobertura: composta por forro horizontal com placas de gesso acartonado com espessura de $12,5 \mathrm{~mm}$, com $10 \mathrm{~cm}$ de lã de vidro sobre o forro, com massa específica da ordem de $12 \mathrm{~kg} / \mathrm{m}^{3}$ e condutividade térmica de $0,04 \mathrm{~W} /\left(\mathrm{m}^{\circ} \mathrm{C}\right)$, sob telhado em telhas de fibrocimento com $5 \mathrm{~mm}$ de espessura. A cor externa da superfície das telhas é escura;

- $\quad$ Pesado:

- Paredes internas, externas e lajes de concreto convencional, com $10 \mathrm{~cm}$ de espessura e massa específica da ordem de 2400 $\mathrm{Kg} / \mathrm{m}^{3}$. O acabamento externo das paredes é feito em cores claras;

- Telhado em telhas de fibrocimento, com $6 \mathrm{~mm}$ de espessura, sobre laje horizontal de concreto convencional com $10 \mathrm{~cm}$ de espessura e massa específica da ordem de $2400 \mathrm{~kg} / \mathrm{m}^{3}$. Sobre a laje há $4 \mathrm{~cm}$ de EPS com condutividade térmica de 0,04 $\mathrm{W} /\left(\mathrm{m}{ }^{\circ} \mathrm{C}\right)$ e massa específica da ordem de $20 \mathrm{~kg} / \mathrm{m}^{3}$. A cor externa da superfície das telhas é escura.

\subsection{Dimensões Horizontais dos ambientes}

Tendo como referência o projeto de habitação indicado na Figura 1, desenvolveram-se mais sete projetos, por meio de variações proporcionais nas dimensões horizontais dos dormitórios e da sala, de modo que sua área de piso fosse reduzida a uma taxa de 5\%, até alcançar uma redução de $35 \%$ da sua área original (Figura 2). Adotou-se a referida taxa de redução para se obter informações sobre o efeito de pequenas variações dimensionais da edificação no seu desempenho térmico. Os projetos analisados são nomeados por letras de "a" até " $h$ ", sendo "a" o projeto de referência e " $h$ " o projeto da menor habitação.

Em todas estas situações consideradas, as porcentagens de área envidraçada na fachada dos dormitórios e sala correspondem a $15 \%$ da área de piso destes ambientes e o pédireito é igual a 2,5 m. Estas características atendem aos parâmetros mínimos exigidos para projetos de edificações deste tipo na cidade de São Paulo (São Paulo, 1992). 
Figura 2 - Variações nas dimensões horizontais da habitação, sem escala.
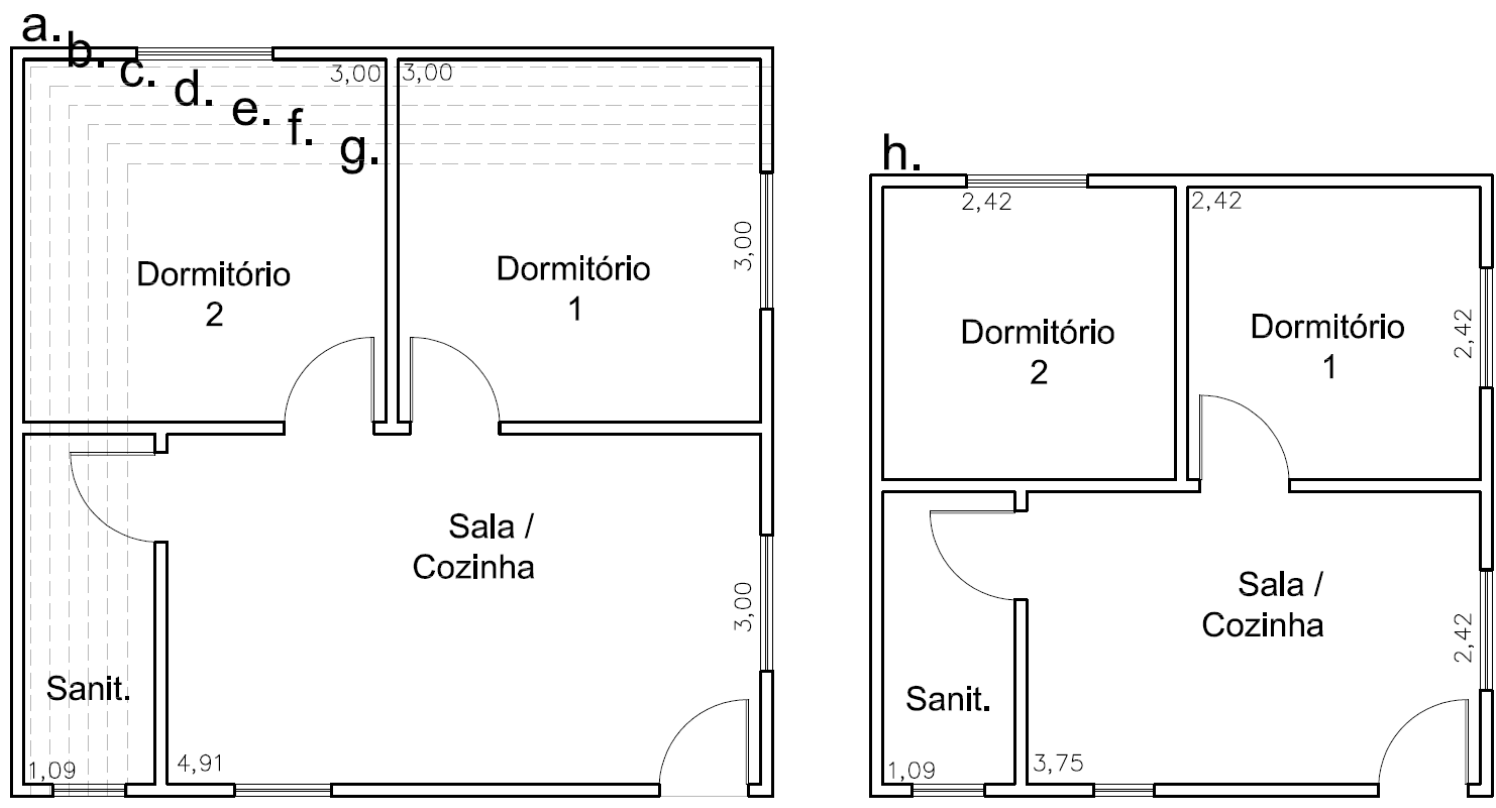

\subsection{Pé-direito dos ambientes}

Os projetos "a" e " $h$ " foram avaliados com variações no pé-direito dos ambientes de 2,5 a $3 \mathrm{~m}$, de $10 \mathrm{em} 10 \mathrm{~cm}$.

\section{5 Área envidraça na fachada de dormitórios e sala}

Nos projetos "a" e "h", efetuaram-se alterações na área envidraçada da fachada dos dormitórios e sala em proporções que correspondem a valores de 15 a $30 \%$ da área de piso destes ambientes.

\section{RESULTADOS}

Os comportamentos térmicos da sala e dormitório apresentam as mesmas tendências, tendo ressalvas quanto ao atendimento do nível "Mínimo" de desempenho térmico somente nas condições de verão. Na condição de inverno, o critério de desempenho térmico "Mínimo" é atendido em todas as situações. Desse modo, são apresentados somente os dados obtidos para o período de verão.

Observa-se que variações proporcionais nas dimensões horizontais dos ambientes, mantendo-se a proporção de área envidraçada da fachada em relação à sua área de piso, produziram diferenças pouco significativas na resposta térmica destes recintos, conforme apresentado na Figura 3.

Estas tendências ocorreram também nas situações em que houve alteração somente na altura do pé-direito dos cômodos dos projetos "a" e "h" como indicado na Figura 4. 
Figura 3 - Temperatura máxima do ar no interior da sala em função do tamanho do ambiente.

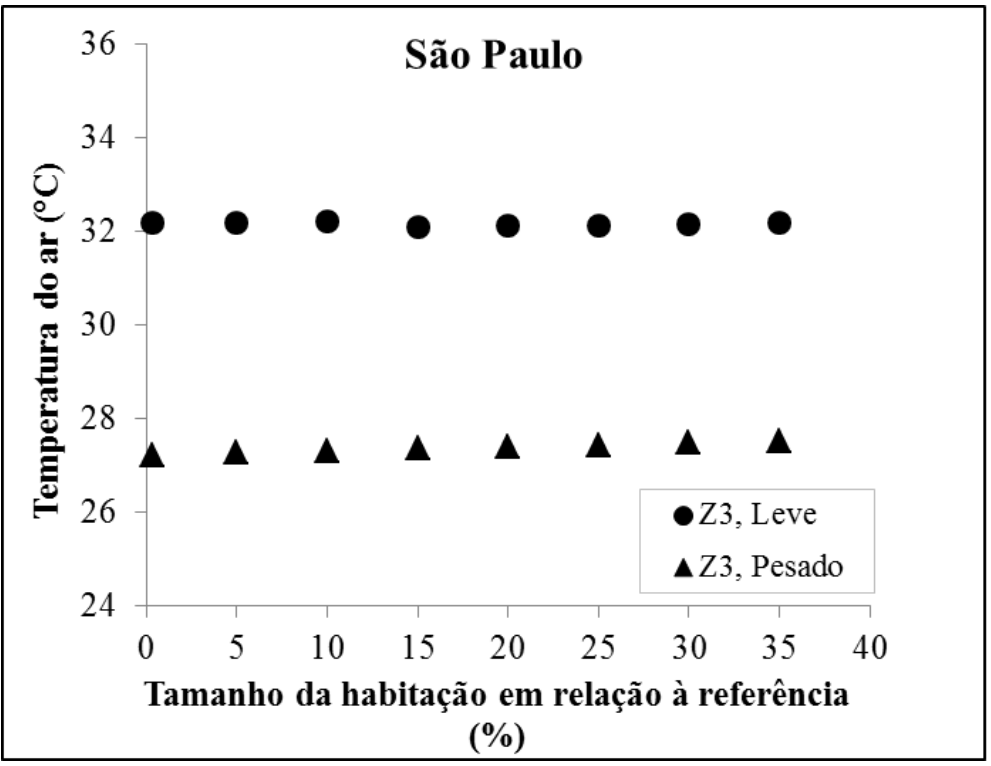

Figura 4 - Temperatura máxima do ar no interior da sala em função do pé direito do ambiente, considerando a habitação de referência "a".

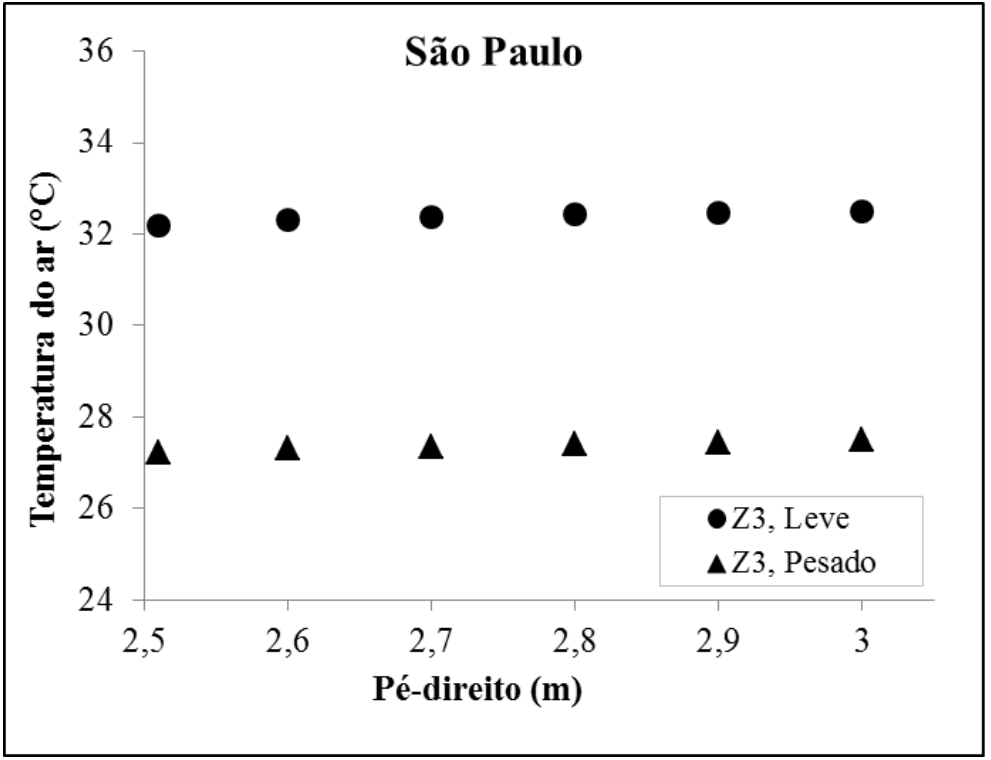

O sistema construtivo teve um papel determinante do nível de desempenho térmico da habitação. Com o sistema construtivo "leve", obteve-se um valor da temperatura máxima do ar interior acima do valor máximo da temperatura do ar exterior, o que não proporciona o atendimento do nível "Mínimo" de desempenho térmico (Figura 5).

Em contrapartida, com o sistema construtivo "pesado" ocorreu uma redução expressiva no valor da temperatura máxima do ar interior em comparação com o valor da temperatura máxima do ar exterior, promovendo o atendimento do nível "Superior" de desempenho térmico.

Esses resultados representam uma situação crítica, em que não se utilizam de artifícios de projeto, como o sombreamento das janelas, ou de uso, como a ventilação seletiva dos 
ambientes. Estes dois fatores poderiam contribuir para a melhoria do desempenho térmico da edificação.

Figura 5 - Perfil horário das temperaturas do ar no interior da sala da habitação de referência "a" no verão, em São Paulo.

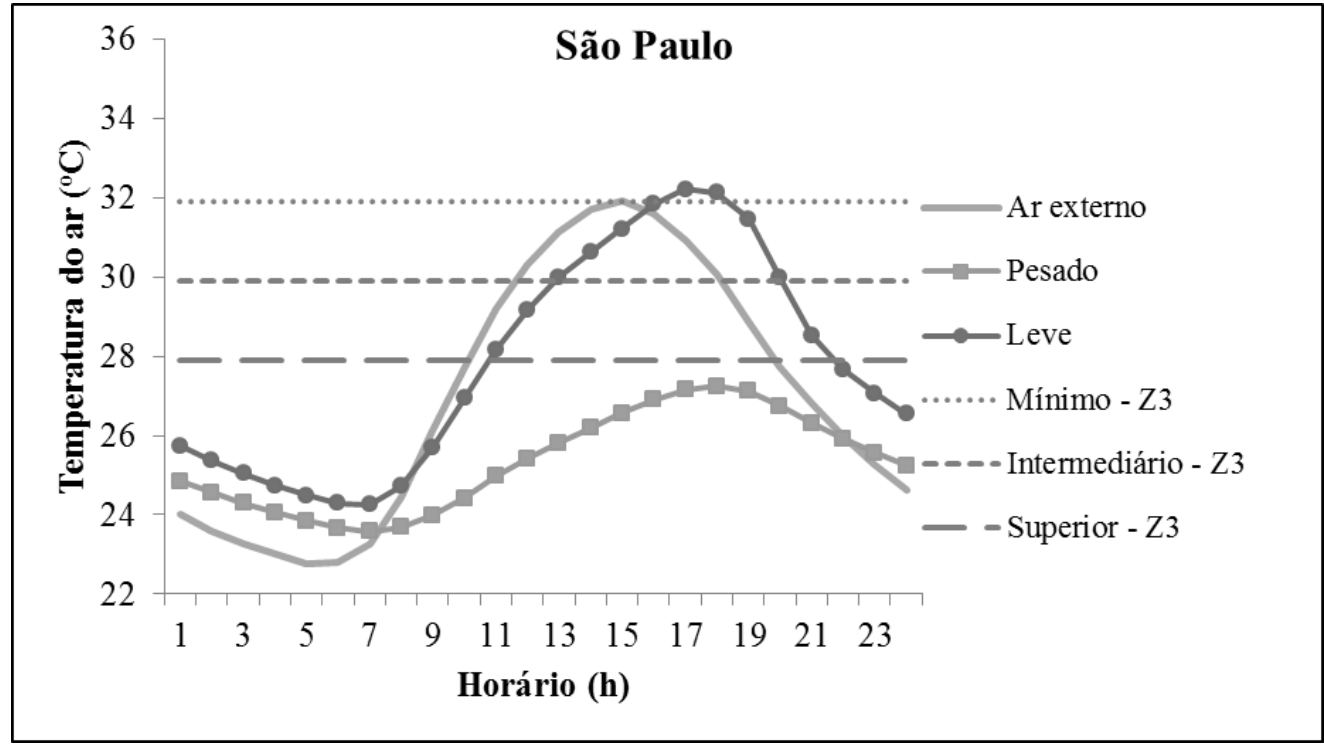

Variações proporcionais na área envidraçada da fachada do ambiente afetaram de modo significativo a temperatura máxima do ar interior (Figura 6) apenas nos edifícios com sistema construtivo "leve", em que um acréscimo de 5\% na área envidraçada da fachada produz uma elevação de aproximadamente $1{ }^{\circ} \mathrm{C}$ no valor da temperatura máxima do ar interno. Com o sistema "pesado", em situação correlata, ocorre uma elevação da ordem de $0,2{ }^{\circ} \mathrm{C}$ no valor da temperatura máxima do ar interior.

Figura 6 - Temperatura máxima do ar no interior da sala em função da área envidraçada na fachada, considerando a habitação de referência "a".

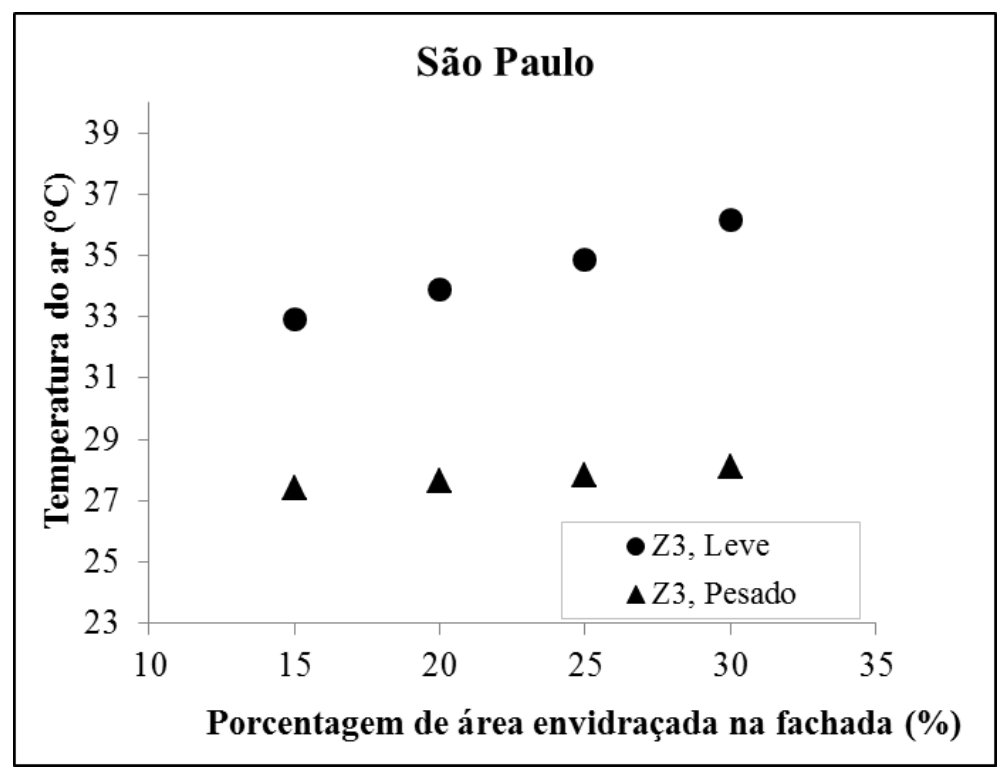




\section{CONCLUSÕES}

Variações proporcionais nas dimensões horizontais dos ambientes de habitações térreas de interesse social, reduzindo ou aumentando a sua área de piso em até $35 \%$ da área original, não produzem efeitos significativos no seu desempenho térmico. Isso é valido somente se forem mantidas as demais características da habitação, especialmente as proporções entre a área envidraçada na fachada e a área de piso de cada recinto.

Também é possível afirmar que, para este tipo de habitação, considerando-se um pédireito mínimo nos ambientes de $2,5 \mathrm{~m}$, variações de até $0,5 \mathrm{~m}$ não irão afetar $\mathrm{o}$ desempenho térmico dos ambientes de modo significativo.

Por outro lado, variações na área envidraçada da fachada devem ser efetuadas com base em estudos específicos para se garantir que não irão prejudicar o desempenho térmico do ambiente. Um acréscimo de 5\% na área envidraçada da fachada pode acarretar uma elevação da temperatura máxima do ar interno de $1{ }^{\circ} \mathrm{C}$, na edificação de baixa inércia térmica. Cabe ressaltar que isto depende também das condições climáticas do local em que está implantada a edificação.

No momento da escolha do sistema construtivo, o empreendedor precisa ter em mente que sistemas construtivos leves têm seu desempenho térmico afetado de modo mais significativo por variações no projeto, o que torna inviável a generalização dos resultados da avaliação de um determinado projeto.

\section{REFERÊNCIAS}

ASSOCIAÇÃO BRASILEIRA DE NORMAS TÉCNICAS (ABNT). NBR-15575-1: Edifícios Habitacionais de até Cinco Pavimentos - Desempenho. Rio de Janeiro, 2013.

COMPANHIA DE DESENVOLVIMENTO HABITACIONAL E URBANO (CDHU). Caderno de Tipologias. 1997.

CHAN, D. et al. Thermal evaluation of strategies for an adequate housing in arid zones and their impact on energy saving. International Conference of the International Building Performance Simulation Association. Kioto, Japão, 1999.

GREGORY, K. et al. Effect of thermal mass on the thermal performance of various Australian residential constructions systems. Energy and Buildings. 40, 2008. 459-465.

São Paulo (Cidade) Código de Obras e Edificações do Município de São Paulo; Lei no 11.228, de 25 de junho de 1992. Dispõe sobre as regras gerais e específicas a serem obedecidas no projeto, licenciamento, execução, manutenção e utilização de obras e edificações. São Paulo: Classe A, 1992.

VERBEKE, S. Thermal Inertia for small scale residential building. Building Performance Simulation in a Changing Environment. Viena: 2010. 